\title{
QUESTÕES DA OBMEP ADAPTADAS: ANÁLISE DE ERROS E O SOFTWARE GEOGEBRA
}

\author{
ADAPTED OBMEP QUESTIONS: ERROR ANALYSIS AND THE GEOGEBRA SOFTWARE
}

THAÍS VENDRUSCOLO*

SANDRA ELIZA VIELMO**

\section{RESUMO}

No presente artigo são apresentados os resultados decorrentes da pesquisa de mestrado Vendruscolo (2019), que teve por objetivo propor estratégias de resolução com o auxílio do software GeoGebra e verificar como a re/construção geométrica de forma dinâmica colabora na diferenciação/compreensão das grandezas perímetro e área. As questões adaptadas da segunda etapa foram concebidas a partir da análise de erros cometidos pelos alunos nas resoluções de questões da OBMEP adaptadas da primeira etapa, segundo classificação de Radatz (1979). A pesquisa foi realizada em uma escola pública do Rio Grande do Sul e contou com a participação de doze alunos do $7^{\circ}, 8^{\circ}$ e $9^{\circ}$ anos do Ensino Fundamental. Com base nas respostas dos questionários inicial e final, do quadro resumo e das análises das resoluções das questões, verificou-se que a análise de erros e o GeoGebra contribuíram no desenvolvimento da diferenciação/compreensão das grandezas perímetro e área no grupo de alunos.

Palavras-chave: Perímetro. Área. OBMEP. Análise de erros. GeoGebra.

\section{ABSTRACT}

This paper presents the results of the master research Vendruscolo (2019), which aimed to propose resolution strategies with the help of GeoGebra software and to verify how the dynamic geometric re/construction contributes to the differentiation / comprehension of quantities perimeter and area. The questions adapted from the second stage were conceived from the analysis of errors made by the students in the resolutions of OBMEP adapted questions from the first stage,according to the classification of Radatz (1979). The research was carried out in a public school in Rio Grande do Sul and had the participation of twelve students from the 7th, 8th and 9th grades of elementary school. Based on the answers of the initial and final questionnaires, the summary table and the analysis of the question resolutions, it was found that the error analysis and GeoGebra contributed to the development of differentiation/ understanding of the perimeter and area quantities in the group of students.

Keywords: Perimeter. Area. OBMEP. Error analysis. GeoGebra.

\footnotetext{
* Mestre em Educação Matemática (UFSM). Docente da Rede Pública Estadual (RS). E-mail: thaisvendruscolo@gmail.com. Orcid: https:// orcid.org/0000-0001-7466-5767

** Doutora em Matemática Aplicada (UFRGS). Docente do Departamento de Matemática (UFSM). E-mail: sandravielmo@gmail.com. Orcid: https://orcid.org/0000-0002-1506-7115
} 


\section{INTRODUÇÃO}

É visível que a matemática, desde a antiguidade, desempenha um papel significativo na tomada de decisões e sob este aspecto, Moura (2011) destaca que o homem é movido por necessidades e que, muitas vezes, a matemática contribui para a solução destas. Convergindo com essas ideias, Pinto $(2000$, p. 17) ressalta que "numa sociedade cada vez mais complexa e tecnicizada, saber matemática é uma necessidade fundamental."

0 ensino de matemática não tem produzido resultados satisfatórios, pois os alunos apresentam baixo desempenho e/ou altas taxas de reprovações na disciplina de Matemática. Particularmente, em relação à geometria, os alunos apresentam dificuldades em relação ao seu aprendizado e, principalmente, em fazer conexões desta área com sua realidade. Muitas vezes, o professor não sabe como desenvolver esse conteúdo e justificativas para essa situação são várias. Uma delas pode estar relacionada com a metodologia adotada pelos mesmos ao ensinar os conteúdos de forma tradicional, não possibilitando o desenvolvimento de atitudes e capacidades intelectuais, que são fundamentais para despertar a curiosidade dos alunos e torná-los capazes de lidar com novas situações.

Além disso, os erros cometidos pelos alunos na disciplina de matemática são considerados inaceitáveis, por grande parte dos professores. Também, é comum as atividades serem avaliadas como certas ou erradas, sem a preocupação de investigar o "porquê" dos resultados, principalmente em relação aos erros.

0 ensinar e 0 aprender estão sendo desafiados, pois as tecnologias estão cada vez mais ao alcance dos alunos e dos professores. Nesse sentido, para Richit, Farias e Faria (2016, p. 273): "... 0 uso da tecnologia no contexto escolar, além de ser fundamental para a formação do professor no cenário atual de educação, é também um estímulo para os alunos se descobrirem como parte integrante de uma sociedade que constantemente se transforma.". Nesse contexto, é perceptível que os professores contam com diversos softwares educacionais que trabalham com conteúdos matemáticos de todos os níveis de ensino, possibilitando o enriquecimento de suas aulas, além de contemplar as diferentes formas de aprendizagens presentes nos seus alunos. Um recurso bastante difundido atualmente é 0 GeoGebra, que reúne recursos de geometria, álgebra e cálculo, além de tabelas, gráficos, probabilidade e estatística.

A partir destas considerações, a pesquisa teve como objetivo analisar as resoluções de algumas questões da Olimpíada Brasileira de Matemática das Escolas Públicas (OBMEP) adaptadas e a partir da análise de erros cometidos pelos alunos, propor estratégias de resolução com o auxílio do GeoGebra, a fim de verificar como a reconstrução geométrica de forma dinâmica colabora na compreensão dos conceitos de perímetro e área.

Justifica-se que a escolha por questões da OBMEP como meio de aplicação da pesquisa, deve-se ao fato da pesquisadora, enquanto professora de Matemática na Educação Básica, constatar que a maioria dos alunos não apresenta interesse em realizar as provas, além de a orientadora desempenhar o papel de coordenadora regional desta olimpíada. Destaca-se que estas questões diferem das questões usuais dos livros didáticos, pois enfatizam a utilização do raciocínio lógico nas resoluções, o que é considerado muito difícil pelos alunos. 


\section{FUNDAMENTAÇÃO TEÓRICA}

\section{PESQUISAS RELACIONADAS}

Com a finalidade de identificar a existência de pesquisas relacionadas ao tema, que fornecessem subsídios para 0 desenvolvimento das etapas e respectivas atividades, foi consultado o Banco de Teses e Dissertações da Coordenação de Aperfeiçoamento de Pessoal de Nível Superior (CAPES). Foram selecionadas pesquisas que mais se aproximavam ao objeto de estudo, ou seja, que envolvessem, além das grandezas perímetro e área, também a análise de erros e/ou GeoGebra. As cinco dissertações de mestrado identificadas e descritas em Vendruscolo (2019) são:

- Machado (2011) teve por objetivo desenvolver atividades dinâmicas utilizando o GeoGebra com o intuito de favorecer o pensamento reflexivo de um grupo de alunos do sétimo ano do Ensino Fundamental, segundo a teoria de John Dewey, para que esses pudessem atribuir significados aos conceitos de perímetro e área.

- Fusiger (2015) teve por objetivo analisar os erros cometidos por um grupo de alunos do terceiro ano do Ensino Médio no cálculo de perímetros e áreas de figuras planas e buscou elaborar estratégias metodológicas para superar as dificuldades através da utilização de um objeto de aprendizagem.

- Assumpção (2015) teve por objetivo elaborar, aplicar e avaliar uma proposta didática com 0 uso do GeoGebra, a partir dos subsídios teóricos indicados pela teoria de registros de representação semiótica, de Duval, com um grupo de alunos do sétimo ano do Ensino Fundamental.

- Ballejo (2015) teve por objetivo investigar de que forma o software GeoGebra pode auxiliar estudantes do sexto ano do Ensino Fundamental a compreender os conceitos de perímetro e área de polígonos, tendo como referencial as teorias Construcionista, de Papert e da Aprendizagem Significativa, de Ausubel..

- Ferreira (2016) teve por objetivo investigar como se dá a integração das tecnologias no ensino e aprendizagem de geometria, com foco no estudo de área e perímetro, em um grupo de alunos do nono ano do Ensino Fundamental. Para tal, propôs uma sequência didática de atividades utilizando o GeoGebra, cuja análise ocorreu a partir da Teoria Antropológica do Didático (TAD).

Observa-se que estas pesquisas não abordam simultaneamente as quatro palavras-chave perímetro, área, análise de erros e GeoGebra e nenhuma utiliza as provas da OBMEP como meio de aplicação, demonstrando a relevância da presente pesquisa.

\section{O ENSINO DE GEOMETRIA: PERÍMETRO E ÁREA}

A geometria, como uma área da matemática, estuda espaço, formas e suas propriedades, além de estar presente nas mais diferentes formas e situações do cotidiano, onde os conhecimentos geométricos são essenciais para seu desenvolvimento. Conforme afirma Lorenzato (1995)

[...] sem estudar Geometria as pessoas não desenvolvem o pensar geométrico ou o raciocínio visual e, sem essa habilidade, elas dificilmente conseguirão resolver as 
situações de vida que forem geometrizadas; também não poderão se utilizar da Geometria como fator altamente facilitador para a compreensão e resolução de questões de outras áreas de conhecimento humano. (LORENZATO, 1995, p. 5)

De acordo com os Parâmetros Curriculares Nacionais (BRASIL, 1998) e a Base Nacional Comum Curricular (BRASIL, 2017) fica explicito que a geometria é uma área da matemática muito importante, pois seu estudo favorece o desenvolvimento de habilidades visuais, do raciocínio geométrico e da argumentação lógica, além da aplicação na solução de problemas associados às diversas áreas do conhecimento humano.

É notório que a visualização e o pensamento geométrico são processos que se complementam, possibilitando uma melhor compreensão direcionada e estruturada de diferentes conceitos matemáticos. Para Fainguelernt (1999) a visualização é a habilidade de perceber, representar, transformar, descobrir, gerar, comunicar, documentar e refletir sobre as informações visuais. Com isso, percebe-se que visualização, não significa apenas avistar, mas sim produzir uma imagem mental.

Corroborando com essas ideias, Leivas (2009, p. 22) , destaca que visualizar é "um processo de formar imagens mentais, com a finalidade de construir e comunicar determinado conceito matemático, com vistas a auxiliar na resolução de problemas analíticos ou geométricos". 0 mesmo, destaca a importância de trabalhar atividades por meio da visualização, por ser um instrumento fundamental para que ocorra a compreensão de objetos abstratos pelo aluno.

Como afirma Lorenzato (1995, p. 5), "a Geometria está por toda parte", ..., mas é preciso conseguir enxergá-la", por isso é importante que os professores se apropriem de metodologias alternativas e/ou de apoio no processo de ensino, de modo a tornar o ensino de geometria mais atrativo e garantir resultados satisfatórios na aprendizagem dos alunos. Logo, torna-se indiscutível a importância de estudar os conceitos geométricos, como por exemplo, o estudo das grandezas perímetro e área, os quais estão presentes no cotidiano dos alunos, além de suas aplicações em diversos contextos.

Os PCN (BRASIL, 1998) enfatizam a confusão dos alunos em relação às noções de perímetro e área, associando, por exemplo, o fato de uma figura ter a maior área, ter, obrigatoriamente, o maior perímetro, o que não é verdade. Além disso, destaca a ênfase no uso mecânico de fórmulas, as quais podem ser esquecidas facilmente. Como possível causa, ressaltam a carência da relação de perímetro e área de forma simultânea em situações-problemas, isto é:

[...] variando as situações propostas (comparar duas figuras que tenham perímetros iguais e áreas diferentes ou que tenham áreas iguais e perímetros diferentes; duas figuras de modo que uma tenha maior perímetro e menor área que a outra ou maior perímetro e maior área) e solicitando aos alunos que construam figuras em que essas situações possam ser observadas, cria-se a possibilidade para que compreendam os conceitos de área e perímetro de forma mais consistente. (BRASIL, 1998, p. 131)

Nesse sentido, os PCN e a BNCC, trazem algumas orientações quanto as grandezas perímetro e área, onde deve-se trabalhar o reconhecimento de figuras geométricas, a composição e decomposição de figuras planas conhecidas, além de situações em que o perímetro e a área são iguais, um maior que 0 outro ou vice-versa. 


\section{ANÁLISE DE ERROS}

No âmbito escolar, a avaliação é uma prática indispensável, porém no processo de ensino e aprendizagem, normalmente serve apenas de classificação. Assim, na maioria das vezes, os erros são interpretados de forma negativa por parte dos professores, sendo relacionados às falhas e equívocos dos alunos. Apesar dos professores saberem que erros ocorrem no processo de ensino e aprendizagem, alguns não percebem que os mesmos podem ser usados para investigar como ocorreu o processo de aquisição do conhecimento ou a falha deste, por parte do aluno. Dessa forma, Pinto (2000) destaca que: "Diferentemente das didáticas tradicionais, em que o erro servia, geralmente, como indicador de fracasso do aluno, nas novas teorias ele se apresenta como um reflexo do pensamento da criança, sendo percebido como manifestação positiva de grande valor pedagógico." (PINTO, 2000, p. 10)

Neste sentido, a produção escrita dos alunos pode ser considerada como uma poderosa ferramenta de análise, pois possibilita detectar as dificuldades apresentadas por eles, contribuindo para novas estratégias de ensino e, nessa perspectiva, Cury (2007) afirma que:

a análise das respostas, além de ser uma metodologia de pesquisa, pode ser, também, enfocada como metodologia de ensino, se for empregada em sala de aula, como "trampolim para a aprendizagem" (BORASI, 1995), partindo dos erros detectados e levando os alunos a questionar suas respostas, para construir o próprio conhecimento. (CURY, 2007, p. 15)

Nesse contexto, surge a análise de erros com a finalidade de contribuir com os professores, fazendo com que eles percebam o raciocínio dos alunos. Para Cury (2007, p. 15), "analisar as produções é uma atividade que traz, para o professor e para os alunos, a possibilidade de entender, mais de perto, como se dá a apropriação do saber pelos estudantes", ou seja, é importante que o erro seja visto como uma metodologia de ensino, a fim de contribuir no processo de construção do conhecimento do aluno, além de fazer com que ele questione suas respostas, gerando uma reflexão no seu processo de aprendizagem

A análise de erros é uma metodologia que busca identificar as causas dos erros cometidos pelos alunos, a fim de auxiliar o professor a buscar novas alternativas e estratégias de ensino, com o intuito de melhorar a aprendizagem dos envolvidos. No entanto, identificar as dificuldades do aluno e contemplar o erro como fator positivo no seu desenvolvimento não é uma tarefa fácil para os professores.

Segundo Cury (2007) a análise de erros é uma tendência em Educação Matemática e destaca que:

[...] as pesquisas sobre erros na aprendizagem de Matemática devem fazer parte do processo de formação dos futuros professores, pois, ao investigar erros, ao observar como os alunos resolvem um determinado problema, ao discutir as soluções com os estudantes, os licenciandos em Matemática estão refletindo sobre 0 processo de aprendizagem nessa disciplina e sobre as possíveis metodologias de ensino que vão implementar no início de suas práticas, podendo ajudar seus alunos logo que detectarem alguma dificuldade. (CURY, 2007, p 95)

Nessa perspectiva, é possível encontrar diversos trabalhos relacionados a análise de erros, que classificam e/ou quantificam os erros, como também os que, além disso os utilizam para rever estratégias metodológicas para o ensino. Pesquisas como De La Torre (2007) e Radatz (1979) propu- 
seram classificações dos erros, as quais são utilizadas por outros pesquisadores. Entretanto, existem pesquisadores que preferem criar suas próprias classificações, baseadas em seus conhecimentos e no material coletado por meio das resoluções.

Nesta pesquisa, a análise dos erros cometidos pelos alunos será efetivada segundo a classificação de erros proposta por Radatz (1979), que os classifica em:

- Erros devido a linguagem (E1): relacionados à interpretação do problema e coleta de dados no texto;

- Erros devido a informações espaciais (E2): relacionados à interpretação do problema e coleta de dados em uma figura;

- Erros devido a pré-requisitos (E3): relacionados a falta de conhecimentos prévios como habilidades, fatos e conceitos;

- Erros devido a rigidez de pensamento (E4): relacionados à insistência do aluno em permanecer no mesmo erro, fazendo associações incorretas; e

- Erros devido a estratégias irrelevantes (E5): relacionados ao aluno utilizar estratégias ou aplicações de regras inadequadas para a resolução das atividades.

\section{TECNOLOGIAS DE INFORMAÇÃO E COMUNICAÇÃO NA EDUCAÇÃO}

Com 0 avanço das tecnologias, a utilização de recursos digitais no ambiente escolar, pode se tornar uma poderosa ferramenta no processo de ensino e aprendizagem do aluno, possibilitando ao professor aulas diferenciadas e mais estimulantes. Para Allevato (2005) estudos apontam que 0 computador se mostrou um instrumento ao ser aliado às atividades de resolução de problemas, as quais visam a construção de novos conhecimentos. Nesse sentido, para Rolkouski (2011) as tecnologias colaboram na organização do pensamento e são capazes de transformar exercícios tradicionais em problemas interessantes.

Segundo a BNCC, uma das competências da área de matemática é a utilização de ferramentas, como as tecnologias digitais, a fim de "modelar e resolver problemas cotidianos, sociais e de outras áreas de conhecimento, validando estratégias e resultados." (BRASIL, 2017, p. 265). Ainda, os PCN destacam que "em Matemática existem recursos que funcionam como ferramentas de visualização, ou seja, imagens que por si mesmas permitem compreensão ou demonstração de uma relação, regularidade ou propriedade" (BRASIL, 1998, p. 45). Seguindo o mesmo ponto de vista, para Leivas (2013), a visualização é uma poderosa ferramenta na resolução de problemas, pois:

[...] a possibilidade de os alunos fazerem mudanças instantâneas em suas representações visuais acrescenta uma dimensão dinâmica na construção do conhecimento. As tecnologias computacionais e, particularmente, os softwares de Geometria Dinâmica, parecem estar despertando para uma nova forma de reconstruir os aspectos visuais da Geometria. As construções, em geral, não precisam ser refeitas, como no caso com régua, compasso e outros instrumentos, pois os softwares permitem reconstruções rápidas, sem perda daquilo que o estudante já realizou (LEIVAS, 2013, p. 1431)

Dessa forma, a partir dos diversos softwares educacionais disponíveis, destaca-se 0 GeoGebra desenvolvido por Markus Hohenwarter, da Universidade de Salzburg, é um software gratuito, de código aberto e disponível em vários idiomas, que foi desenvolvido para o ensino e aprendizagem 
de matemática nos vários níveis de ensino, reunindo diversos recursos e ferramentas totalmente dinâmicas, contribuindo para a elaboração de materiais didáticos. Segundo Beltrami (2016, p. 80) "0 software GeoGebra apresenta grandes atrativos que nos ajudam a compreender melhor problemas geométricos", favorecendo os processos de visualização de objetos matemáticos, pois as funções de arrastamento e manipulação permitem que se construam relações, sem que suas propriedades sejam alteradas ou perdidas.

Assim, a utilização de tecnologias deve servir para o enriquecimento do ambiente educacional e contribuir para a construção do conhecimento do aluno. Contudo, para que isso ocorra é necessário que o professor domine os recursos utilizados e esteja preparado para possíveis imprevistos, contribuindo para um aprendizado com significado para 0 aluno.

\section{PROCEDIMENTOS METODOLÓGICOS}

Os sujeitos da pesquisa foram alunos do $7^{0}, 8^{\circ}$ e $9^{\circ}$ anos do Ensino Fundamental da Escola Estadual de Educação Básica João XXIII, situada da cidade de São João do Polêsine, RS, no primeiro semestre de 2019 , onde a pesquisadora atuava como professora titular da disciplina de matemática apenas na turma de $8^{\circ}$ ano.

A pesquisa foi desenvolvida em quatro momentos:

Primeiro momento: aplicação do questionário inicial, constituído de perguntas fechadas, que solicitavam informações como idade, ano escolar, conhecimentos sobre as grandezas perímetro e área, dentre outras consideradas pertinentes. Após, a resolução de três questões da OBMEP adaptadas. Para a formulação destas foram selecionadas questões comuns às provas dos níveis N1 e N2, que envolviam as grandezas perímetro e área. Analisando-as, constatou-se que poucas abordavam a grandeza perímetro e, desta forma, houve a necessidade de adaptá-las, sendo possível questionamentos a respeito desta grandeza.

Segundo momento: análise do questionário inicial e dos erros cometidos pelos alunos nas resoluções das questões propostas, classificando-os segundo a categorização de Radatz (1979).

Terceiro momento: resolução com auxílio do software GeoGebra de três questões da OBMEP adaptadas, selecionadas de modo a abordar as mesmas competências/habilidades da primeira etapa, finalizando com a aplicação do questionário final.

Quarto momento: análise dos erros cometidos pelos alunos nas resoluções das questões propostas no terceiro momento, segundo Radatz (1979), e do questionário final.

\section{ANÁLISE DOS RESULTADOS}

\section{QUESTIONÁRIO INICIAL}

No primeiro encontro, realizado no contra turno, vinte e três alunos, com idade entre onze e quinze anos, responderam ao questionário. Além disso, verificou-se que nove estão cursando $07^{0}$ ano do Ensino Fundamental, sete estão no $8^{\circ}$ ano e sete no $9^{\circ}$ ano. A seguir serão analisadas algumas questões.

Sobre os conteúdos matemáticos de perímetro e área, foi solicitado que indicassem qual o nível de conhecimento que acreditavam possuir. A partir do Gráfico 1, percebe-se que a maioria acreditava ter um bom conhecimento. 
Gráfico 1 - Conhecimento dos alunos sobre as grandezas perímetro e área

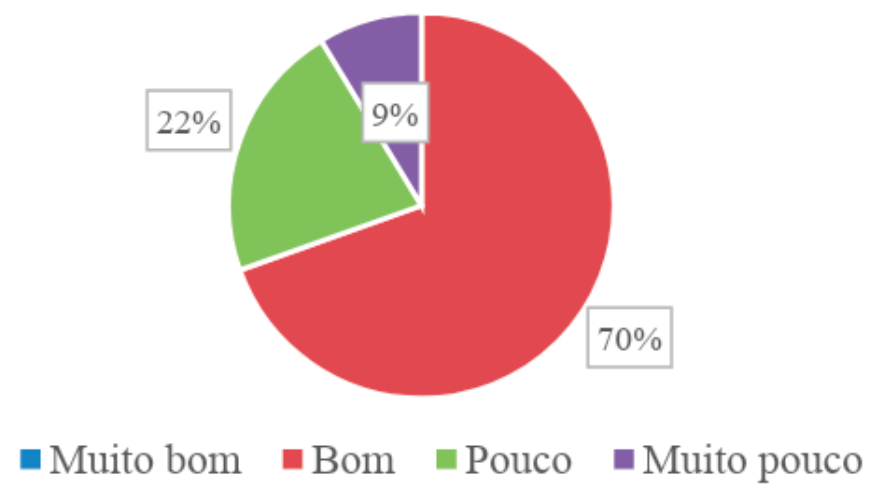

Fonte: dados da pesquisa.

Em relação à questão que trazia uma situação contextualizada, era solicitado que os alunos calculassem o perímetro e a área de um terreno retangular com medidas e . A partir das respostas, pode-se concluir que a maioria dos alunos não compreendem os conceitos das grandezas perímetro e área, fazendo confusões, como por exemplo, que perímetro e área são iguais, além das dificuldades em trabalhar com variáveis, contrariando de certa forma a opinião emitida por eles na pergunta anterior.

\section{ANÁLISE DAS QUESTÕES: PRIMEIRA ETAPA}

A partir dos registros escritos pelos alunos nas resoluções das questões da OBMEP adaptadas, não foi possível obter dados suficientes para realizar a análise de erros, pois a grande maioria não desenvolveu seus cálculos ou apenas colocou respostas sem sentido. Acredita-se que este comportamento esteja relacionado com a visão que os alunos têm das provas da OBMEP, pois acham difíceis e não se sentem motivados a realizá-las. Assim, a fim de conseguir dados para a análise, um novo encontro foi realizado. Inicialmente, foi proposta uma aula prática, na qual os alunos puderam medir o quadro branco e a sala de aula e, a partir dessas medições, obter os valores das grandezas perímetro e área. Além disso, a pesquisadora levou encartes de lojas, onde os alunos escolheram pisos para revestir o chão da sala de aula e analisar o custo financeiro. A seguir, os alunos refizeram as três questões da OBMEP adaptadas, propostas no primeiro encontro.

Para a análise de erros foram considerados os registros escritos das resoluções apenas dos doze alunos que participaram integralmente da pesquisa. A fim de manter o sigilo da identidade, os mesmos foram identificados pela letra $A$, seguido pelos números 7,8 ou 9 , dependendo do ano que frequentam no Ensino Fundamental e, por último, números de 1 a 6 para $07^{0}$ ano e de 1 a 3 para os alunos do $8^{\circ}$ e $9^{\circ}$ anos.

Inicialmente, as respostas dos alunos em cada item das questões foram distribuídas em correta, parcialmente correta, incorreta ou em branco e, posteriormente, a partir dos registros escritos foram analisados e classificados os erros, segundo Radatz (1979). Cabe salientar que a classificação feita pela pesquisadora foi baseada nos seus conhecimentos e experiências profissionais como professora e que outro pesquisador poderia analisar e classificar os erros cometidos de forma diferente. 
Questão 1 (2013): Dafne tem muitas peças de plástico: quadrados amarelos de lado , quadrados azuis de lado e triângulos retângulos verdes cujos lados menores medem e, como mostrado à direita.

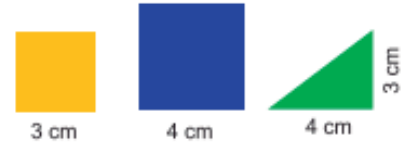

a) Com estas peças e sem sobreposição, ela forma figuras como, por exemplo, o hexágono à direita. Qual é o perímetro e a área deste hexágono?

b) Usando somente peças quadradas, Dafne formou a figura ao lado, com um buraco em seu interior.

Qual é o perímetro e a área do buraco?

Qual é o perímetro e a área da figura hachurada?
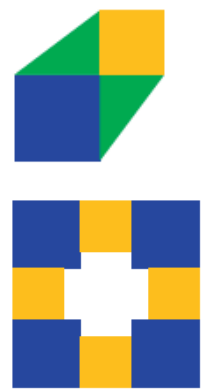

Objetivo da questão: analisar e reconhecer figuras geométricas conhecidas e, a partir destas perceber a composição e decomposição de novas figuras sem sobreposição, como proposto nos PCN (BRASIL, 1998) e na BNCC (BRASIL, 2017). em branco.

0 Gráfico 2 ilustra a distribuição das respostas em correta, parcialmente correta, incorreta ou

Gráfico 2 - Distribuição das respostas - Questão 1.

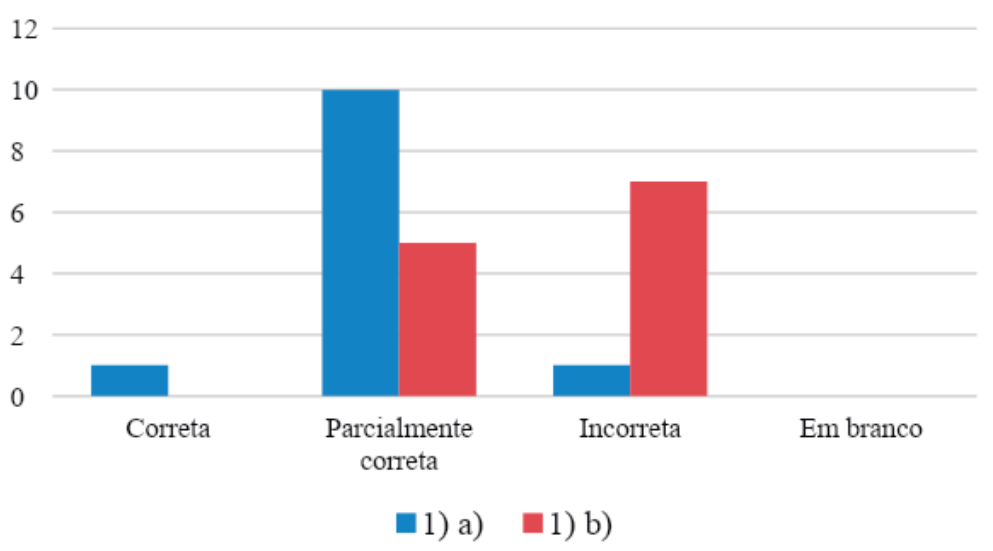

Fonte: Dados da pesquisa.

No item a) desta questão, o erro mais frequente se referiu ao cálculo da área do triângulo, o que implicou em erro no cálculo da área do hexágono (erro E3). Além disso, três alunos multiplicaram os três lados distintos 3, 4 e 5 do hexágono. Em relação ao item b), o erro mais frequente se refere a obtenção de informações espaciais a partir da visualização das figuras geométricas e suas composições a partir de figuras já conhecidas (erro E2). Esse fato fica explícito, pois a grande maioria dos alunos calculou o perímetro da parte hachurada sem considerar o contorno interno. 
Questão 2 (2015): Lucinha tem três folhas retangulares iguais, cujos lados medem $20 \mathrm{~cm}$ e $30 \mathrm{~cm}$, conforme figura ao lado.

a) Qual o perímetro e a área de cada folha?

b) Lucinha fez dois traços retos na primeira folha, um a da margem esquerda e outro a $7 \mathrm{~cm}$ da margem superior, dividindo-a em quatro retângulos. Um desses retângulos tem a maior área. Qual é o valor dessa área?

c) 0 retângulo de maior área do item b) também possui o maior perímetro?

d) Ajude Lucinha a dividir a segunda folha em quadrados iguais, desenhando traços paralelos às margens, de modo que esses quadrados tenham a maior área possível.

e) Lucinha pegou a terceira folha, amarela na frente e verde no verso, e fez duas dobras: a primeira a $8 \mathrm{~cm}$ da margem esquerda e a segunda a uma certa distância da margem inferior, de forma que 0 perímetro da região não coberta da folha (contorno da região amarela da última figura) fosse de 54 $\mathrm{cm}$. Qual é a distância da segunda dobra à margem inferior?

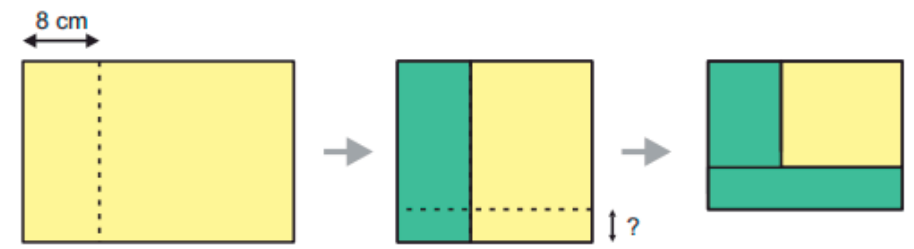

Objetivo da questão: identificar figuras planas e maximizar perímetro e área, além de verificar situações como indicadas no item c), propostas nos PCN (BRASIL, 1998).

0 Gráfico 3 ilustra a distribuição das respostas em correta, parcialmente correta, incorreta ou em branco.

Gráfico 3 - Distribuição das respostas - Questão 2.

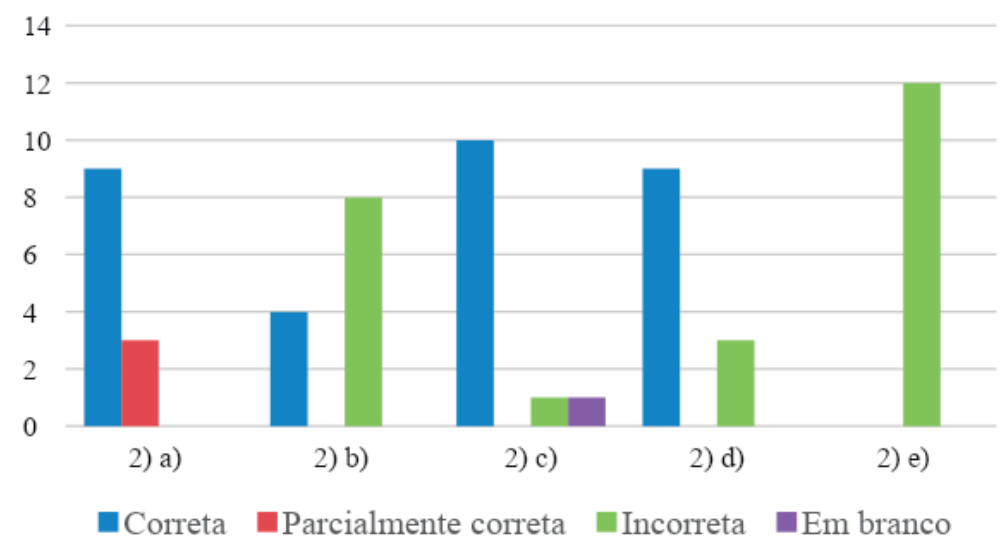

Fonte: Dados da pesquisa. 
Nesta questão destaca-se a dificuldade dos alunos em extrair as informações do texto ou da figura, além da falta de habilidade dos pré-requisitos. Além disso, destaca-se a dificuldade dos alunos na associação das unidades de medida de área, onde a maioria usava a mesma unidade de perímetro (erros E1/E2/E3). No item e), não houve acertos. No entanto, o aluno A73 apresentou o raciocínio correto, onde na primeira dobra, descontou corretamente $0 \mathrm{~s} 16 \mathrm{~cm}$, obtendo a medida da base da região amarela igual a . Como no enunciado é dado que o perímetro da região amarela é $54 \mathrm{~cm}$, ele deveria calcular a altura dessa região e realizou tentativas de associar valores até atingir o perímetro dado no enunciado, mas errou uma das somas e, consequentemente, o resultado final.

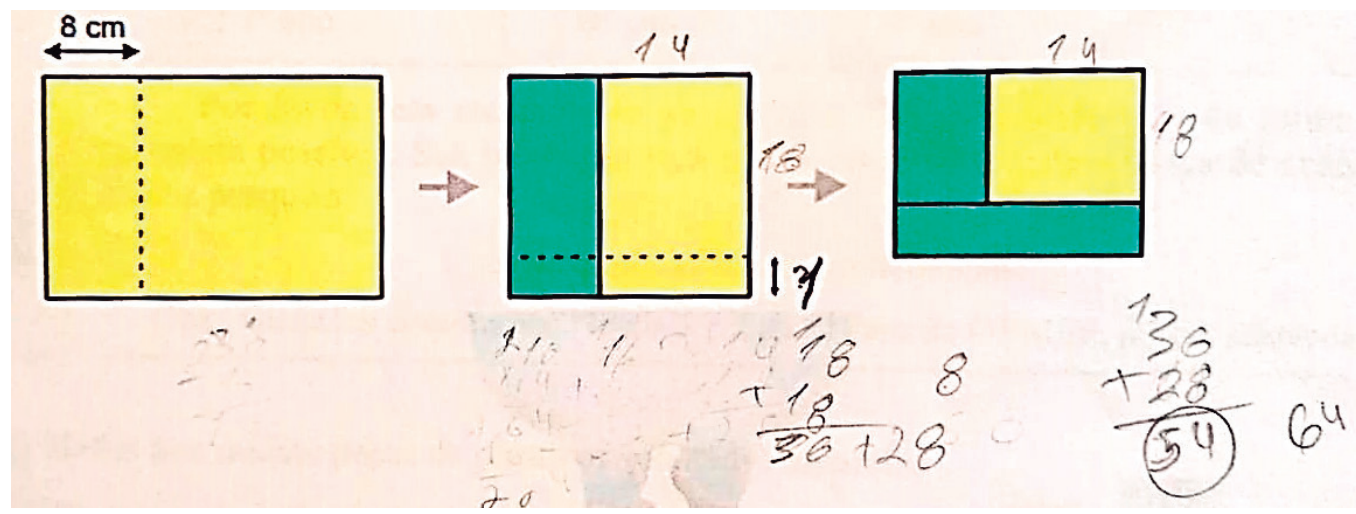

Questão 3 (2016): A peça ilustrada ao lado é formada por quatro quadradinhos de $1 \mathrm{~cm}$ de lado. Observe que o perímetro desta peça, ou seja, a medida de seu contorno é de $10 \mathrm{~cm}$.

Roberto forma figuras juntando duas dessas peças, sem sobreposição e fazendo coincidir lados de quadradinhos.

a) Roberto formou a figura ao lado. Qual o perímetro e a área desta figura?

b) Ajude Roberto desenhando uma figura com perímetro igual a $12 \mathrm{~cm}$ no quadriculado da esquerda e outra com perímetro igual a $18 \mathrm{~cm}$ no quadri-

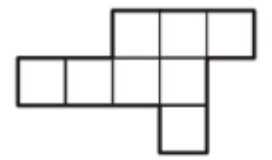
culado da direita. Calcule a área das figuras formadas.

c) Comparando os valores das grandezas perímetro e área das figuras formadas no item b), o que você pode concluir?

Objetivo da questão: observar que figuras com diferentes perímetros podem ter mesma área, sendo essa uma das situações propostas pelos PCN (BRASIL, 1998).

0 Gráfico 4 ilustra a distribuição das respostas em: correta, parcialmente correta, incorreta ou em branco. 
Gráfico 4 - Distribuição das respostas - Questão 3.

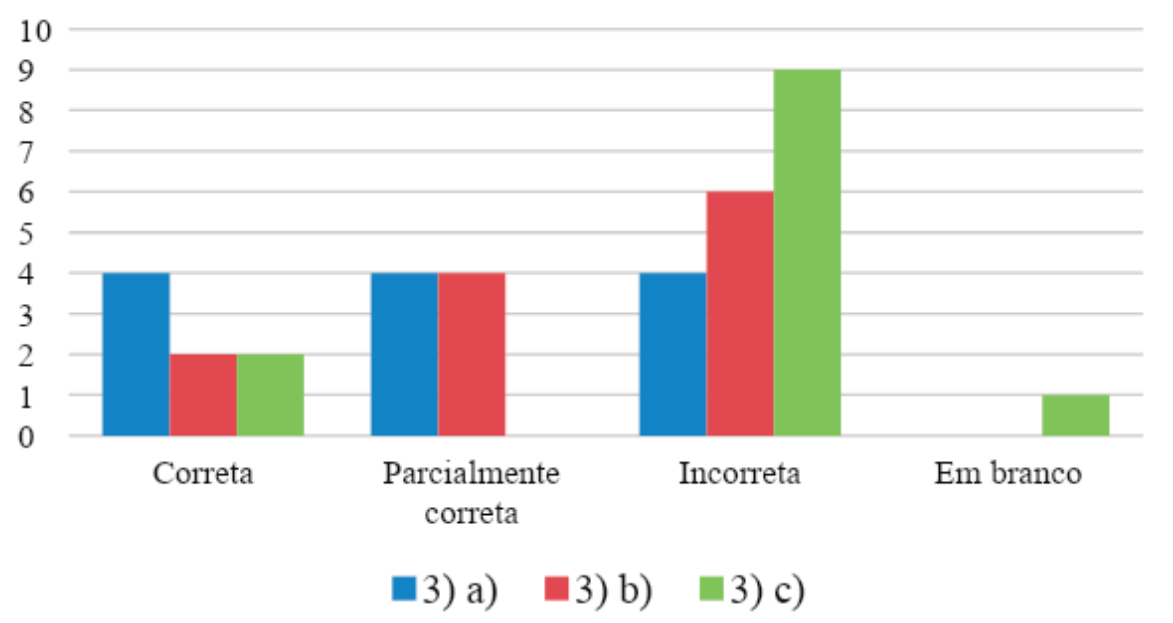

Fonte: dados da pesquisa.

Na questão 3 percebeu-se a grande dificuldade dos alunos em extrair informações do enunciado do problema e a falta de habilidade em formar figuras formadas por peças em malhas quadriculadas, apesar da situação simplificada desta peça ser formada por quadrados de $1 \mathrm{~cm}$ de lado e área $4 \mathrm{~cm}^{2}$ (erros E1/E2). Pelo fato da maioria dos alunos não terem interpretado corretamente as informações indicadas no texto, ocorreram respostas inesperadas de alunos que construíram as figuras com três ou mais peças com formato em L ou não, apesar destas duas exigências constarem no enunciado da questão.

\section{ANÁLISE DAS QUESTÕES: SEGUNDA ETAPA}

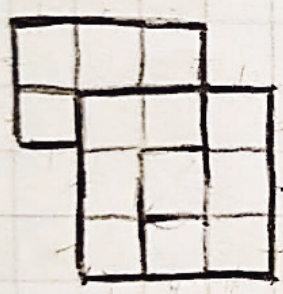

Figura com perimetro igual a $12 \mathrm{~cm}$

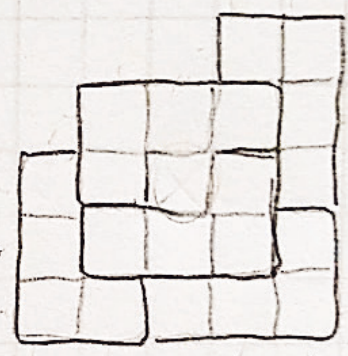

Figura com perimetro igual a $18 \mathrm{~cm}$

A escolha das questões da OBMEP adaptadas aplicadas nesta etapa, ocorreu a partir das percepções da pesquisadora quanto à categorização dos erros nas resoluções das questões aplicadas 
na primeira. A execução da segunda etapa ocorreu em dois encontros no contra turno, onde no primeiro a pesquisadora usou o projetor multimídia para expor as ferramentas do GeoGebra que os alunos iriam utilizar, visto que nenhum deles conhecia 0 aplicativo e foram desenvolvidas duas questões. Ao final da resolução de cada uma, foi solicitado que preenchessem um quadro resumo com as respostas de suas resoluções. No segundo encontro foi desenvolvida a última questão e preenchido 0 quadro resumo relativo a esta questão. As construções destas três questões podem ser visualizadas no repositório do GeoGebra Tube ${ }^{1}$, no e-book intitulado "OBMEP: Perímetro e Área".

Questão 1 (2006): Uma folha retangular de altura $10 \mathrm{~cm}$ e base $15 \mathrm{~cm}$ foi cortada ao longo das linhas tracejadas AC e BD em quatro pedaços: dois triângulos iguais e dois polígonos iguais de cinco lados cada um, como na figura ao lado.

Os segmentos $A C$ e BD têm o mesmo comprimento e se encontram no centro do retângulo formando ângulos retos.

a) Qual o perímetro da folha retangular $\left(\mathrm{P}_{\text {folla }}\right)$ ?

b) Qual a área da folha retangular $\left(A_{\text {folla }}\right)$ ?

c) Qual é o polígono formado pelos vértices A, B, C e D?

d) Qual a área de um pedaço triangular?

e) Qual a área de um pedaço de cinco lados?

Com os quatro pedaços, podemos montar um quadrado com um buraco retangular, como na figura ao lado.

f) Qual o perímetro do buraco $\left(P_{\text {buraco }}\right)$ ?

g) Qual a área do buraco $\left(A_{\text {buraco }}\right)$ ?

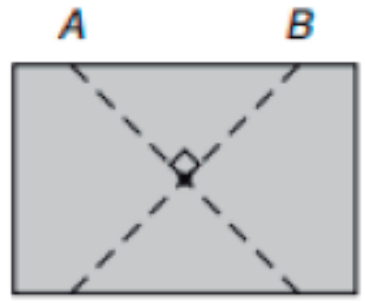

D

C

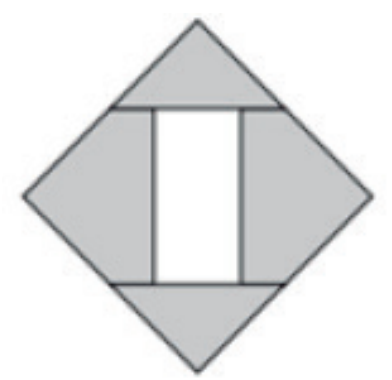

Considerando uma folha de altura $10 \mathrm{~cm}$ e base a, variando de $10 \mathrm{~cm}$ a $20 \mathrm{~cm}$, e a construção apresentada no arquivo do GeoGebra, responda:

h) Qual o valor da base a para que o perímetro e a área do buraco sejam iguais?

i) Quais os valores da base a para que o perímetro do buraco seja menor que a área do buraco?

j) Quais os valores da base a para que o perímetro do buraco seja maior que a área do buraco?

Objetivo da questão: Trabalhar a composição e decomposição de figuras planas e situações em que o perímetro e a área são iguais, uma maior que a outra ou vice-versa, destacadas nos PCN (BRASUL, 1998) e na BNCC (BRASIL, 2017).

0 Gráfico 5 ilustra a distribuição das respostas em correta, parcialmente correta, incorreta ou em branco.

1 Atividades disponíveis em: https://www.geogebra.org/. 
Gráfico 5 - Distribuição das respostas: Questão 1 - $2^{\mathrm{a}}$ Etapa

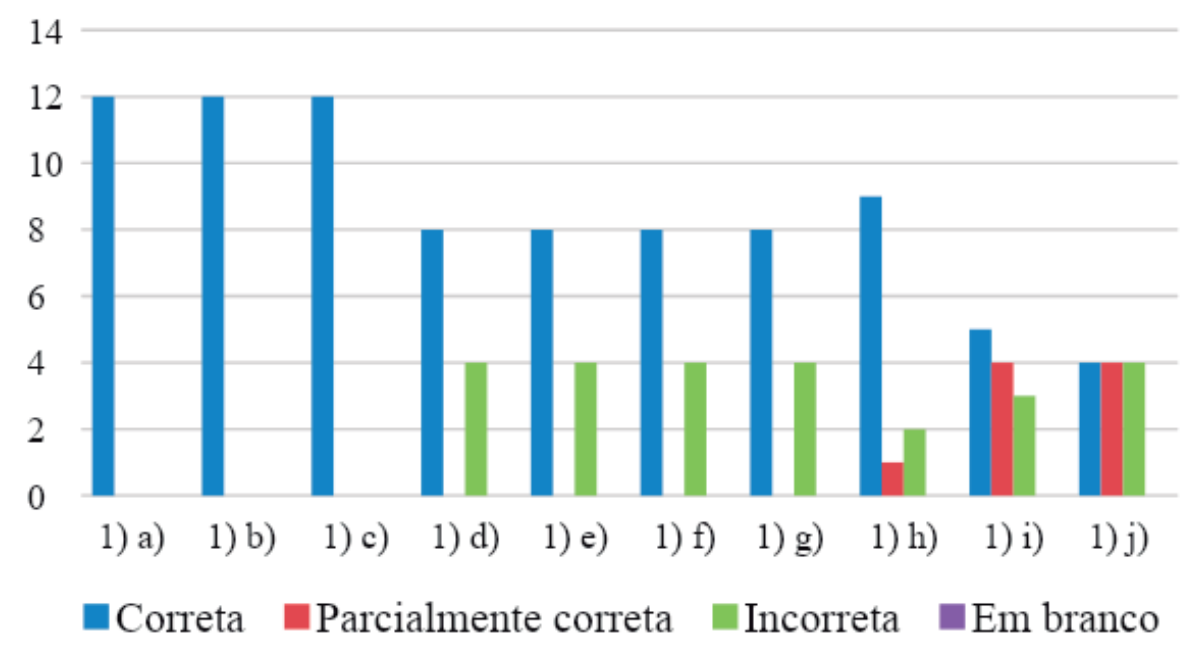

Fonte: dados da pesquisa.

Nesta questão percebeu-se a dificuldade da maioria dos alunos em trabalhar com números reais e com intervalos, apesar do segundo não ter sido ainda trabalhado em sala de aula, mas tiveram 0 auxílio da pesquisadora (erros E2/E3). Por exemplo, nos itens i) e j), 0 aluno A83 apresentou apenas os valores inteiros para, tendo dificuldades em perceber que os números reais também faziam parte desse intervalo. Para a resolução dos itens h), i) e j) destaca-se a importância da ferramenta controle deslizante do GeoGebra, pois permitiu aos alunos a visualização geométrica da variação da medida da base, apesar de não terem concluído esta variação algebricamente.

i) Quais os valores da base a para que o perimetro do buraco seja menor que a área do buraco? de 10 j 17 .

j) Quais os valores da base a para que o perimetro do buraco seja maior que a área do buraco? $18 \div 20$

Questão 2 (2008): A figura ao lado representa o terreno de Dona Idalina. Esse terreno é dividido em duas partes por uma cerca, representada pelo segmento . A parte triangular tem área igual a $120 \mathrm{~m}^{2}$, o lado mede $23,3 \mathrm{~m}$ e 0 lado $A E$ mede $14,2 \mathrm{~m}$.

a) Qual a área do trapézio?

b) Qual é o perímetro total do terreno $\left(P_{\text {terreno }}\right)$ ?

c) Qual é a área total do terreno $\left(A_{\text {terreno }}\right)$ ?

d) A partir do protocolo, entregue pela pesquisadora, construa o terreno de Dona Idalina no GeoGebra;

e) Dona Idalina quer fazer uma nova cerca, representada pelo segmento $A F$ na figura ao lado, de modo a dividir o terreno em duas partes de mesma área. Qual deve ser a medida do segmento CF?

f) 0 comprimento da nova cerca permanece 0 mesmo? Justifique.

g) Após fazer a nova cerca, o que aconteceu com o perímetro e a área do terreno de Dona Idalina? Justifique.
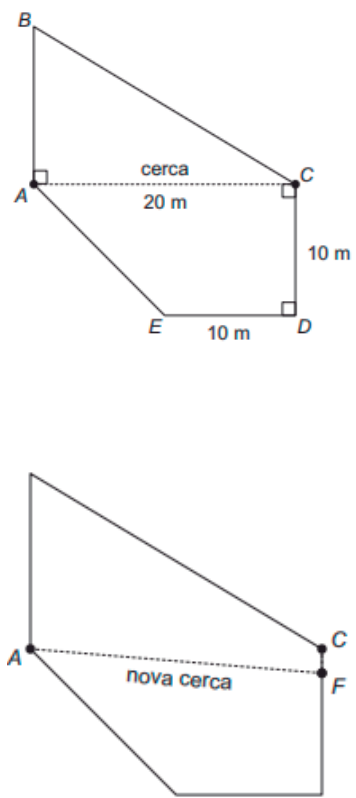
Objetivo da questão: analisar o comportamento de perímetro e áreas. Esse tipo de atividade é destacado na BNCC (BRASIL, 2017), onde uma das habilidades é resolver problemas com situações envolvendo medidas de terrenos.

0 Gráfico 6 ilustra a distribuição das respostas em correta, parcialmente correta, incorreta ou em branco.

Gráfico 6 - Distribuição das respostas: Questão 2 - 2ª Etapa

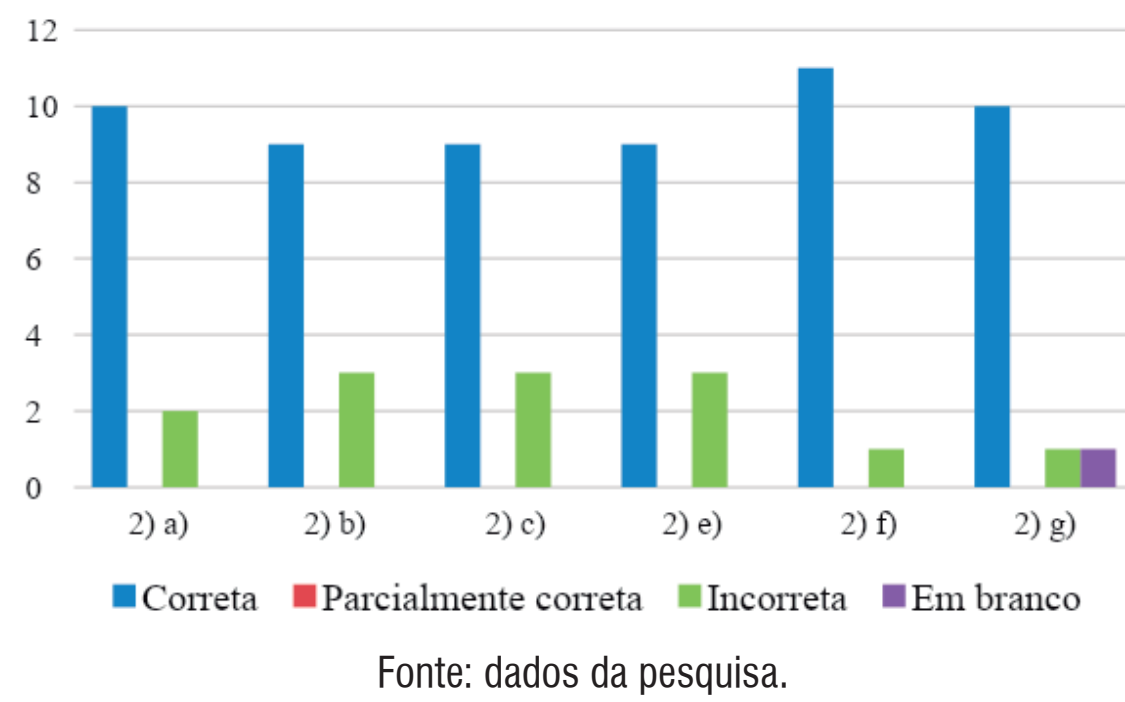

Nesta questão, a maioria dos alunos acertou todos os itens. Apenas A71 e A76 apresentaram dificuldades tanto em conceitos prévios (erro E3), quanto em obter dados do enunciado e de figuras (erros E1/E2). Destaca-se a importância da ferramenta de arrastamento de um ponto do GeoGebra, pois permitiu aos alunos a determinação da medida do segmento e as conclusões dos itens f) e g), fato que pode ser visualizado conforme movimentam a cerca, ou seja, quando movimentam o ponto , além das medidas do perímetro e área que não mudam.

Questão 3 (2012): Uma contaminação em um tabuleiro $5 \times 5$, formado por quadrados de de lado, propaga-se em estágios de acordo com as seguintes regras:

- Quadrados contaminados, indicados em cinza, permanecem contaminados no estágio seguinte;

- Um quadrado não contaminado, indicado em branco, torna-se contaminado no estágio seguinte quando tem pelo menos dois lados comuns com quadrados contaminados; caso contrário, permanece não contaminado; e

- A contaminação acaba quando não é possível contaminar novos quadrados.

a) Represente no arquivo do GeoGebra o primeiro e segundo estágios de contaminação ilustrados nas figuras abaixo. 


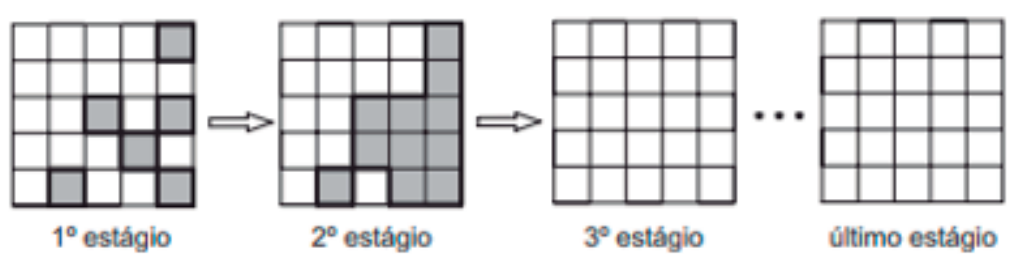

Definimos o perímetro de contaminação de um estágio, como sendo a medida do contorno da região contaminada. Por exemplo, os perímetros de contaminação do primeiro e do segundo estágios são $P_{1}=24 \mathrm{~cm} \mathrm{e} P_{2}=20 \mathrm{~cm}$, indicados pelas linhas em destaque nas figuras do item a).

Definimos a área de contaminação de um estágio, como sendo a soma das áreas dos quadrados contaminados. Por exemplo, as áreas de contaminação do primeiro e do segundo estágios são $A_{1}=6 \mathrm{~cm}^{2}$ e $A_{2}=11 \mathrm{~cm}^{2}$, indicadas pelos quadrados cinza nas figuras do item a).

Represente no arquivo do GeoGebra, disponibilizado pela pesquisadora, o terceiro estágio de contaminação e responda:

b) Qual é o perímetro de contaminação do terceiro estágio $\left(\mathrm{P}_{3}\right)$ ?

Qual é a área de contaminação do terceiro estágio $\left(\mathrm{A}_{3}\right)$ ?

Represente no arquivo do GeoGebra, disponibilizado pela pesquisadora, o último estágio de contaminação e responda:

d) Qual é o perímetro de contaminação do último estágio $\left(P_{U}\right)$ ?

e) Qual é a área de contaminação do último estágio $\left(A_{\cup}\right)$ ?

Objetivo da questão: reconhecer o quadrado de medida unitária, trabalhar com malhas quadriculadas e comparar medidas de perímetro e área. Espera-se que os alunos observem que o perímetro do terceiro e do último estágio são iguais, mas suas áreas são diferentes, situações propostas nos PCN (BRASIL, 1998).

0 Gráfico 7 ilustra a distribuição das respostas em correta, parcialmente correta, incorreta ou em branco.

Gráfico 7 - Distribuição das respostas: Questão 3 - 2ª Etapa

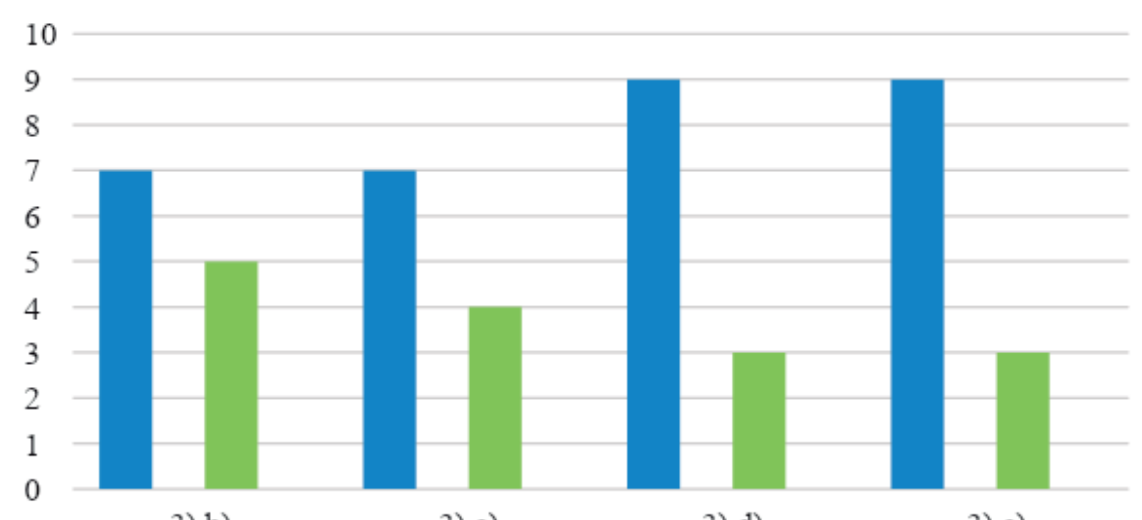

3) b)

3) c)

3) d)

3) e)

घCorreta $\square$ Parcialmente correta Incorreta $\square$ Em branco 
d) Qual é o perímetro de contaminação do último estágio $\left(\mathrm{P}_{\mathrm{U}}\right)$ ? $20 \mathrm{~cm}$

e) Qual é a área de contaminação do último estágio $\left(\mathrm{Au}_{\mathrm{U}}\right)$ ? $18 \mathrm{~cm}^{2}$

Fonte: dados da pesquisa.

Nesta questão pode-se perceber que alguns alunos ainda continuavam com dificuldades de trabalhar com material quadriculado de medidas unitárias (erro E3), onde se destaca a confusão entre as grandezas perímetro e área.

0 GeoGebra teve um papel importante no desenvolvimento da questão, pois foi utilizado na forma de um jogo de contaminação, contribuindo para uma melhor visualização de forma dinâmica e atrativa do quadrado unitário e da comparação de perímetro e área. No material disponível, cada estágio de contaminação era associado a uma cor, que facilitava a distribuição dos próximos estágios, conforme as regras indicadas no enunciado da questão.

\section{COMPARAÇÃO ENTRE AS ETAPAS DE APLICAÇÃO}

A partir das análises realizadas nas três questões da primeira etapa, pode-se concluir, de forma geral, que os erros mais frequentes estão relacionados a dificuldade de obter informações espaciais, ou seja, visualizar e explorar figuras, interpretando e retirando os dados necessários (erro E2). Outro erro frequente é o pouco domínio associado a diferenciação/compreensão das grandezas perímetro e área (erro E3). Ademais, pode-se destacar a dificuldade dos alunos em trabalhar com questões mais elaboradas, que exijam maior interpretação e raciocínio.

Na segunda etapa, a partir das respostas ao questionamento proposto "A partir das resoluções das três questões propostas e do quadro resumo acima, faça considerações a respeito do seu entendimento sobre as grandezas matemáticas perímetro e área", percebe-se a dificuldade dos alunos em expressar suas percepções através da escrita, pois as respostas são vagas. Apesar disso, ao longo do desenvolvimento das etapas da pesquisa, percebeu-se um grande crescimento dos alunos em relação aos seus conhecimentos sobre as grandezas perímetro e área.

\section{ANÁLISE DO QUESTIONÁRIO FINAL}

A primeira pergunta estava relacionada à abordagem da pesquisa e questionou se a mesma auxiliou na sua aprendizagem, onde dez alunos responderam que sim e dois mais ou menos. As justificativas mais frequentes foram que a pesquisa os auxiliou a relembrar as grandezas perímetro e área, além do GeoGebra agilizar as resoluções das questões. Caso tivessem respondido sim ou mais ou menos à primeira pergunta, a segunda solicitava que indicassem quais as atividades que mais contribuíram e as mais citadas foram aquelas realizadas com 0 auxílio do GeoGebra. É perceptível que os alunos, nos dois questionamentos anteriores, destacam o software, justificando que o mesmo tornou as atividades mais atrativas e agradáveis de resolver.

A terceira pergunta estava relacionada com a utilização do GeoGebra, se o mesmo contribuiu para uma maior diferenciação/compreensão das grandezas perímetro e área, sendo que nove responderam que sim e três mais ou menos. As justificativas estavam relacionadas com a facilitação e agilidade nas resoluções das questões, além da sua dinamicidade. 
A última pergunta teve a finalidade de verificar se a maneira como a pesquisa foi desenvolvida proporcionou mudanças quanto ao modo de pensar/visualizar a matemática, onde seis responderam que sim, quatro mais ou menos e dois responderam que não. As justificativas para as respostas sim e mais ou menos, foram que as questões auxiliaram a relembrar as grandezas envolvidas, além de fazê-los raciocinar. Em relação as duas repostas negativas, um dos alunos justificou que continua não gostando da matemática e o outro continua gostando da mesma maneira.

\section{CONSIDERAÇÕES FINAIS}

Como pode-se perceber ao decorrer desta pesquisa, a análise de erros como metodologia de ensino (CURY, 2007), propiciada a partir da produção escrita dos alunos, pode colaborar no processo de construção do conhecimento do mesmo. Cabe ao professor identificar os erros cometidos pelos alunos e buscar novas alternativas e estratégias de ensino, que possam contribuir para o desenvolvimento do conhecimento do aluno. Para isso, o professor precisa mudar sua prática pedagógica e umas das alternativas é a utilização de tecnologias digitais, as quais estão cada vez mais presentes e acessíveis nas escolas.

Nesse contexto, tal pesquisa teve como objetivo analisar as resoluções de algumas questões da OBMEP, adaptadas e, a partir da análise de erros, propor estratégias de resolução com o auxílio do GeoGebra, a fim de verificar como a reconstrução geométrica de forma dinâmica colabora na compreensão dos conceitos de perímetro e área. A partir do desenvolvimento da pesquisa, das análises dos questionários e das resoluções das questões da OBMEP, fica evidente a dificuldade da maioria dos alunos, sujeitos da pesquisa, em relação as grandezas perímetro e área. Uma das possíveis causas é forma de como essas grandezas são, normalmente, trabalhadas em sala de aula, com 0 uso direto de fórmulas, onde as mesmas acabam sendo memorizadas e como destacado em BRASIL (1998), elas podem ser facilmente esquecidas.

Apesar das dificuldades demonstradas inicialmente pelos alunos, pode-se destacar 0 crescimento dos mesmos, durante 0 desenvolvimento da pesquisa, fato constatado nas análises das resoluções das questões da segunda etapa. Essa melhoria está relacionada com a metodologia utilizada, a análise de erros, a qual proporcionou à pesquisadora uma visão diferente dos erros cometidos pelos alunos. Com uma análise cuidadosa, pode-se observar os diferentes tipos de erros e quais suas possíveis causas e, com isso, propor novas estratégias de resolução com o software GeoGebra, 0 qual auxiliou de forma dinâmica nas construções.

A identificação dos erros cometidos pelos alunos não é uma tarefa fácil, como destaca Pinto (2000), pois exige uma mudança no planejamento do professor. Apesar das dificuldades encontradas durante a classificação dos erros nas resoluções das questões, a pesquisadora alcançou os objetivos propostos na pesquisa.

Cury (2007) destaca que a análise de erros pode ser considerada uma metodologia de ensino, quando os erros forem detectados e explorados em sala de aula, a partir de estratégias com a utilização de recursos, como, por exemplo, as tecnologias digitais. A partir do questionamento desta pesquisa, pode-se concluir que a análise de erros, juntamente com o software GeoGebra contribuíram de forma positiva no desenvolvimento da construção do conhecimento do aluno. De certa forma, além de contribuir para a apropriação/diferenciação das grandezas perímetro e área, propiciou uma melhor visualização para a compreensão dos conceitos envolvidos. 
No entanto, apesar da melhoria dos sujeitos da primeira para a segunda etapa, a pesquisadora não pode afirmar que os mesmos, após o desenvolvimento do projeto, saberão diferenciar as grandezas perímetro e área, pois é professora titular apenas da turma de $8^{\circ}$ ano, onde três alunos participaram da pesquisa. Contudo, pode perceber o reflexo do trabalho em um dos alunos da sua turma, pois durante uma avaliação sobre polinômios, em sala de aula, o aluno destacou que lembrava das grandezas, por causa das atividades desenvolvidas na pesquisa.

Dessa forma, acredita-se que tanto a análise de erros, quanto o software GeoGebra podem estar presentes na prática pedagógica dos professores, pois juntos favorecem 0 desenvolvimento do conhecimento, não apenas do aluno, mas do próprio professor. Além disso, a importância de trabalhar com problemas contextualizados, que exigem do aluno o raciocínio, 0 pensar geométrico e a visualização que auxiliam para uma melhor compreensão dos conceitos matemáticos envolvidos.

Cabe salientar a relevância e os benefícios que esta pesquisa proporcionou à pesquisadora, a qual passou a perceber que a análise dos erros cometidos pelos alunos pode ser vista como uma ferramenta inovadora no processo de ensino e aprendizagem. A mesma espera conseguir trabalhar com a análise de erros na sua prática docente, além de utilizar mais recursos que contribuam para 0 desenvolvimento do conhecimento do aluno.

\section{REFERÊNCIAS}

ALLEVATO, N. S. G. Associando o computador à resolução de problemas fechados: Análise de uma experiência. 2005. 370 f. Tese (Doutorado em Educação Matemática) - Universidade Estadual Paulista, Instituto de Geociências e Ciências Exatas, Rio Claro, 2005.

ASSUMPÇÃO, P. G. S de. Perímetro e área: uma engenharia didática utilizando o geogebra sob o olhar das representações semióticas. 2015. 232p. Dissertação (Mestrado em Educação Matemática) - Universidade Federal de Santa Maria, Santa Maria, RS, 2015.

BALLEJO, C. C. Aprendizagem de conceitos de área e perímetro com 0 GeoGebra no $6^{0}$ ano do ensino fundamental. 2015. 143p. Dissertação (Mestrado em Educação em Ciências e Matemática) - Pontifícia Universidade Católica do Rio Grande do Sul, Porto Alegre, RS, 2015.

BRASIL. Secretária de Educação Fundamental. Parâmetros Curriculares Nacionais: matemática. Brasília: MEC, 1998. . Ministério da Educação. Base Nacional Comum Curricular - BNCC. Brasília, DF, 2017.

BELTRAMI, R. S. Algumas técnicas utilizando o software geogebra no processo de resolução de problemas geométricos do ensino básico: situações de máximos e mínimos e lugares geométricos. 2016. 140p. Dissertação (Mestrado Profissional em Matemática em Rede Nacional) - Universidade Federal de Roraima, Boa Vista, RR, 2016.

CURY, H. N. Análise de Erros: 0 que podemos aprender com as respostas dos alunos. Belo Horizonte: Editora Autêntica, 2007.

DE LA TORRE, S. Aprender com os erros: 0 erro como estratégia de mudança. Tradução Ernani Rosa. Porto Alegre: Artmed, 2007. $240 \mathrm{p}$. 
FAINGUELERNT, E. K. Educação matemática: Representação e Construção em Geometria. Porto Alegre: Artes Médicas Sul, 1999.

FERREIRA, E. F. P. A integração das tecnologias digitais ao ensino e aprendizagem de geometria no ensino fundamental anos finais: uma proposta com foco no estudo de perímetro e área de figuras geométricas planas. 2016. 185p. Dissertação (Mestrado Profissional em Educação Matemática) - Universidade Federal de Juiz de Fora, Juiz de Fora- MG, 2016.

FUSIGER, J. M. Análise de erros no cálculo de perímetro e área de figuras planas no ensino médio. 2015. 80p. Dissertação (Mestrado Profissionalizante em Ensino de Física e de Matemática) - Centro Universitário Franciscano, Santa Maria, RS, 2015.

LEIVAS, J. C. P. Imaginação, intuição e visualização: a riqueza de possibilidades da abordagem geométrica no currículo de cursos de licenciatura de matemática. Tese (Doutorado em Educação) - Universidade Federal do Paraná, Curitiba, 2009, $249 \mathrm{p}$.

Resolução de problemas geométricos usando o GeoGebra. In: I Congreso de Educación Matemática de América Central y de El Caribe. 2013. Santo Domingo, República Dominicana. Disponível em: https://bit.ly/39zR51w. Acesso em: 17 mai. 2017.

LORENZATO, S. A. Porque não ensinar Geometria? In: A Educação Matemática em Revista. Blumenau: SBEM, ano III, n. 4,1995 , p. 3-13.

MACHADO, J. P. A. A significação dos conceitos de perímetro e área, na ótica do pensamento reflexivo, trabalhando em ambientes de geometria dinâmica. 2011. 165p. Dissertação (Mestrado Profissional em Educação Matemática) Universidade Federal de Ouro Preto, Ouro Preto, MG, 2011.

MOURA, M. 0. Educar com a Matemática: saber específico e saber pedagógico. Revista Educación y Pedagogía, v. 23, n. 59, 2011.

PINTO, N. B. 0 erro como estratégia didática. São Paulo: Papirus, 2000.

RADATZ, H. Error Analysis in Mathematics Education. Journal for Research in Mathematics Education v. 10, n. 2, p. 163-172. Maio, 1979.

RICHIT, A.; FARIAS, M. M. R.; FARIA, R. W. S. C. Tendências em Educação Matemática no Brasil: Emergências e confluências a partir da noção de tapestry of trends. In: Beatriz Silva D’Ambrosio; Roger Miarka. (Org.). Clássicos na Educação Matemática Brasileira: múltiplos olhares. 1ed. Campinas: Mercado de Letras, v. 7, p. 251-274, 2016.

ROLKOUSKI, E. Tecnologias no ensino de matemática. Curitiba: Ibpex, 2011.

VENDRUSCOLO, T. Análise de erros na resolução de questões da OBMEP: uma proposta de utilização do GeoGebra como recurso didático. 2019. 86p. Dissertação (Mestrado em Educação Matemática) - Universidade Federal de Santa Maria, Santa Maria, RS, 2019.

RECEBIDO EM: 29 out. 2019

CONCLUÍDO EM: 14 fev. 2020 